\title{
Diversity of Iberian nucleopolyhedrovirus wild-type isolates infecting Helicoverpa armigera (Lepidoptera: Noctuidae)
}

\author{
Elisabete Figueiredo ${ }^{\mathrm{a}}$, Delia Muñoz ${ }^{\mathrm{b}}$, Rosa Murillo ${ }^{\mathrm{b}, \mathrm{c}}$, António Mexia ${ }^{\mathrm{a}}$, Primitivo Caballero ${ }^{\mathrm{b}, \mathrm{c}, *}$ \\ a DPPF, Instituto Superior de Agronomia, Universidade Técnica de Lisboa, Tapada da Ajuda. 1349-017 Lisboa, Portugal \\ ${ }^{\mathrm{b}}$ Entomología Agrícola y Patología de Insectos, Departamento de Producción Agraria, Universidad Pública de Navarra, Campus Arrosadía, 31006 Pamplona, Spain

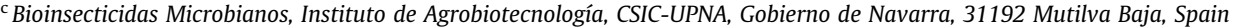

\section{A R T I C L E I N F O}

\section{Article history:}

Received 7 November 2008

Accepted 4 February 2009

Available online 12 February 2009

\section{Keywords:}

Helicoverpa armigera

Tomato fruitworm

Baculovirus

Genotypic variants

Geographical isolate

Pathogenicity

Virulence

\begin{abstract}
A B S T R A C T
Larvae of the tomato fruitworm, Helicoverpa armigera, were surveyed for nucleopolyhedrovirus (NPV) infection (referred to as HearNPV) in three different locations from the Iberian Peninsula: Olivenza and Toledo in Spain and the Oeste region in Portugal. Twenty HearNPV isolates were obtained from single field-collected larval cadavers. Restriction endonuclease (REN) profiles of the collected isolates with BgIII and PstI allowed identification of six different $H$. armigera single-embedded NPV strains in Spain (referred to as HearSP3, HearSP4, HearSP5, HearSP6, HearSP7, and HearSP8) and two in Portugal (referred to as HearPT1 and HearPT2). No strains were shared by isolates from different geographical regions except HearSP5, which was found in isolates from Olivenza and Toledo. Cluster analysis based on the restriction fragment length polymorphisms of these strains in relation to two previously identified strains from Badajoz (HearSP1) and Cordoba (HearSP2) in Spain, showed no correlation among the strains and their geographical origin. The biological activity of HearSP2, HearSP4, HearSP7, HearSP8, HearPT1, and HearPT2 was compared in terms of pathogenicity (50\% lethal concentration, $\mathrm{LC}_{50}$ ) and virulence (mean time to death). HearPT2 and HearSP7 were significantly more pathogenic than HearSP2, with $\mathrm{LC}_{50}$ values 2.8 and 2.6-fold higher than the latter, respectively, on H. armigera second instars. HearSP4 and HearPT2 killed larvae significantly faster than HearSP8, whereas HearSP2, HearSP7, and HearPT1 showed intermediate mean time to death values.
\end{abstract}

(c) 2009 Elsevier Inc. All rights reserved.

\section{Introduction}

Helicoverpa armigera (Hübner), the tomato fruitworm, is an important pest of several crops all over the world except on the American continents (Fitt, 1989). In the Iberian Peninsula, it is a key pest on numerous crops including field-grown tomato, pepper, cotton and maize, protected (i.e., glass and plastic houses) vegetable and ornamental crops such as tomato, sweet pepper, lettuce, roses, and carnations, summer cole crops and strawberry (Torres-Vila et al., 2002; Figueiredo et al., 2006).

Environmental and food residue problems associated with chemical control tactics have encouraged the search for more sustainable pest control measures. Baculoviruses are considered as one of the most interesting insect biological control agents and very promising as biopesticides for their high specificity, virulence, ability to persist in the environment and compatibility with other beneficial natural enemies (parasitoids, predators and pathogens) and chemical pesticides (Harper, 1986). Baculovirus-based insecticides, therefore, have the potential to play an important role in integrated pest

\footnotetext{
* Corresponding author. Fax: +34 948169732 (P. Caballero).

E-mail address: pcm92@unavarra.es (P. Caballero).
}

management (IPM) and organic farming programs. Given the prevalence of $H$. armigera populations showing resistance to a range of chemical insecticides that have already been described worldwide (McCaffery, 1998; Torres-Vila et al., 2002), baculovirus-based products would likely prove useful in Iberia for tomato fruitworm control in several crop systems in rotation with Bacillus thuringiensis Berliner $(\mathrm{Bt})$, and other biorational pesticides. Moreover, the use of nucleopolyhedroviruses (NPVs) (Baculoviridae), other biorationals and Bt in rotation could be a useful tool to retard the development of $\mathrm{Bt}$ resistance in pest populations (Raymond et al., 2006).

Genotypic variants of the same baculovirus, such as those commonly found at different geographical locations and sometimes even in the same host individual, have been reported to differ in their DNA restriction endonuclease (REN) profiles and also in their biological activities (Caballero et al., 1992; Takatsuka et al., 2003; Cory et al., 2005). These differences in pathogenicity and virulence due to natural intraspecific heterogeneity may represent an interesting tool to develop new baculovirus-based bioinsecticides (Moscardi, 1999).

Several NPVs of the single- (SNPV) and multiple-embedded nucleocapsid type (MNPV) have been isolated from H. armigera populations all over the world (Gettig and McCarthy, 1982; Figueiredo et al., 1999; Ogembo et al., 2005; Zhang et al., 2005). Some of them 
have been characterized thoroughly, including two genotypes purified from different Chinese isolates, and their genomes have been entirely sequenced (Chen et al., 2001; Zhang et al., 2005). A H. armigera NPV (HearNPV) isolated in the Chinese province of Hubei has been produced as a biopesticide and extensively used on cotton (Wang et al., 2001), whereas in Thailand, HearNPV isolates are produced locally for control of $H$. armigera in tomato, cotton, and tangerine (Jones et al., 1998). As the use of foreign NPV isolates can have a negative impact on the biological activity of native strains (Muñoz and Caballero, 2000) and different host biotypes can vary in their susceptibility to geographically distinct isolates (Milks, 1997), the selection of indigenous isolates that are suitable for development as biological control agents requires the characterization of the strains present in each geographical region.

Two NPV isolates from the Iberian Peninsula were identified previously (Figueiredo et al., 1999) and characterized as singleembedded NPVs (SNPVs) (Arrizubieta et al., unpublished data). In our present study, larvae of the tomato fruitworm were surveyed for NPV infection in several locations of the Iberian Peninsula. The collected isolates were compared genetically by restriction fragment length polymorphism (RFLP), and biologically by determining their pathogenicity and mean time to death (MTD). In addition, the RFLP profiles of the different distinct isolates were used for a cluster analysis of the isolates.

\section{Materials and methods}

\subsection{Insect rearing}

The $H$. armigera population was maintained at $25 \pm 2{ }^{\circ} \mathrm{C}, 70-80 \%$ relative humidity and $16 \mathrm{~h}: 8 \mathrm{~h}$ day-night photoperiod on a semisynthetic diet based on that described by Poitout and Bues (1974).

\subsection{Helicoverpa armigera larval sampling and virus isolation}

NPV isolates were originally obtained from $H$. armigera larvae with clear signs of patent NPV disease collected in 1999 in two sweet field maize (maize plants and wild host plants) from Olivenza and Toledo (Spain) and in field tomatoes and tomatoes and sweet peppers grown in greenhouses from Oeste (Portugal) (Table 1). Larvae were collected individually into $1.5 \mathrm{ml}$ plastic Eppendorf tubes except some of the samples from Oeste (3-4 larvae per tube), and preserved at -18 or $4{ }^{\circ} \mathrm{C}$ in the dark until diagnosis was done. Each sample was macerated in double distilled water and the presence of occlusion bodies (OBs) was verified by phase contrast microscopy of the homogenated tissue at $400 \times$. A total of 49 samples were examined ( 16 from Spain and 33 from Portugal).

\section{3. $O B$ amplification and purification}

OB samples were multiplied in groups of 10-20 third instars of $H$. armigera. Only one virus sample was produced at each time to prevent cross-contamination. For this, larvae were starved for at least $12 \mathrm{~h}$ and then fed diet plugs that had been surface-contaminated with crude extracts from homogenated NPV-infected larvae. Larvae were reared individually on semi-synthetic diet until death or pupation. Infected larvae were frozen as soon as they died. To purify OBs, dead larvae were macerated in $300 \mu$ ldistilled water, filtered twice through muslin-like tissue and centrifuged at $1600 \mathrm{~g}$ for $5 \mathrm{~min}$ at room temperature. Pellets were resuspended in $1 \mathrm{ml}$ water and $0.5 \mathrm{ml}$ of $0.1 \%$ sodium dodecyl sulphate (SDS) and centrifuged for $5 \mathrm{~min}$ at $1600 \mathrm{~g}$. These pellets were resuspended in $0.3 \mathrm{ml}$ of $0.1 \%$ SDS and the suspensions carefully placed on $0.5 \mathrm{ml}$ of a $40 \%$ sucrose cushion and centrifuged at $23,000 \mathrm{~g}$ during $30 \mathrm{~min}$, resuspended in $1 \mathrm{ml}$ of $0.1 \% \mathrm{SDS}$, centrifuged at $4000 \mathrm{~g}$ for $5 \mathrm{~min}$ and washed twice in distilled water. When necessary, the suspensions were briefly sonicated to break up OB aggregates. Pure $\mathrm{OB}$ pellets were finally resuspended in $0.3 \mathrm{ml}$ distilled water and stored at $-20^{\circ} \mathrm{C}$ for further use. Isolate identity was confirmed after each multiplication by REN digestion and agarose gel electrophoresis (as described in section 2.4 below). Previously identified strains from Spain (HaSP1 and HaSP2, referred as HearSP1 and HearSP2, respectively, in this paper for consistency with ICTV nomenclature) (Figueiredo et al., 1999) and the HearNPV Chinese strain G4 (HearG4 in this paper), whose genome has been completely sequenced (Chen et al., 2001) and was kindly provided by Dr. van Oers (University of Wageningen, The Netherlands), were also multiplied following identical procedures

\subsection{Viral DNA extraction and REN analysis}

Purified $\mathrm{OB}$ suspensions were incubated with one-third volume of $3 \times \operatorname{DAS}\left(0.3 \mathrm{M} \mathrm{Na}_{2} \mathrm{CO}_{2}+0.5 \mathrm{M} \mathrm{NaCl}+0.03 \mathrm{M}\right.$ EDTA, pH 10.5) at $37^{\circ} \mathrm{C}$ for $5 \mathrm{~min}$ to dissolve the polyhedrin matrix. Heavy particles including undissolved OBs were pelleted by $6000 \mathrm{~g}$ centrifugation for $5 \mathrm{~min}$. To rupture virion and nucleocapsid envelopes, virioncontaining supernatants were transferred to sterile $1.5 \mathrm{ml}$ vials and incubated at $45^{\circ} \mathrm{C}$ with $500 \mu \mathrm{g} / \mathrm{ml}$ proteinase $\mathrm{K}$ during $2.5 \mathrm{~h}$ and a further 30 min with $1 \%$ SDS. Viral DNA was extracted once with an equal volume of TE-buffer-saturated phenol and then at least twice with an equal volume of phenol-chloroform-isoamyl alcohol $(25: 24: 1)$ or with chloroform until the interface became completely clean. DNA was precipitated with $10 \%$ (v/v) 3 M sodium acetate ( $\mathrm{pH} 5.2$ ) and twice the volume of ice-cold $96 \%$ ethanol at $12,000 \mathrm{~g}$ for $15 \mathrm{~min}$; then it was washed with $70 \%$ cold ethanol and centrifuged for $5 \mathrm{~min}$. DNA pellets were resuspended in $10 \mathrm{mM}$ Tris- $\mathrm{HCl} \mathrm{pH} 8.0$ and kept at $4{ }^{\circ} \mathrm{C}$ until use.

For REN digestion, 1-2 $\mu \mathrm{g}$ of viral DNA was incubated with $1 \mathrm{U}$ of BglII and PstI according to the supplier's instructions, at $37{ }^{\circ} \mathrm{C}$ for 4-12 h. These RENs were chosen as they allowed proper differentiation of HearNPV strains in previous studies (Figueiredo et al., 1999). Reaction was stopped by the addition of one-sixth volume of $6 \times$ loading buffer $(0.25 \%$ bromophenol blue; $40 \%$ sucrose, $\mathrm{w} /$ v). Fragments were separated by electrophoresis carried out in $0.7 \% \mathrm{TAE}$ agarose gels containing $0.25 \mu \mathrm{g} / \mathrm{ml}$ ethidium bromide at 20-30 V for ca. $14 \mathrm{~h}$ and visualized on a Gel Doc Imaging System (Bio-Rad, Alcobendas, Spain). DNA fragment sizes were estimated by comparison to a standard molecular weight marker (bacteriophage $\lambda$ genomic DNA digested with HindIII) with the aid of Quantity One 4.6 (Bio-Rad). HearSP1 fragments were labelled alphabetically (from A to M with BglII and from A to F for PstI) from higher to lower molecular weight using upper case letters. The

Table 1

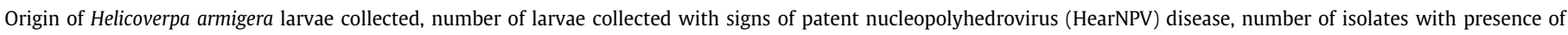
occlusion bodies, and number and nomenclature of the different HearNPV strains identified in each location.

\begin{tabular}{|c|c|c|c|}
\hline Collection sites & No. diseased larvae & No. isolates & No. HearNPV strains (identified strains) \\
\hline Olivenza (Spain) & 7 & 7 & 5 (HearSP3, HearSP4, HearSP5, HearSP6, and HearSP7) \\
\hline Toledo (Spain) & 9 & 3 & 2 (HearSP5 and HearSP8) \\
\hline Oeste (Portugal) & 33 & 10 & 2 (HearPT1, HearPT2) \\
\hline Total & 49 & 20 & 8 \\
\hline
\end{tabular}


polymorphic fragments appearing in the rest of the isolates were labelled with lower case letters referring to the closest fragment of HearSP1 of equal or upper molecular weight followed by a subindex that distinguished polymorphic fragments with the same minor case letter but different molecular weight.

\subsection{Cluster analysis}

A matrix of presence/absence of RFLP fragments was generated based on BglII and PstI restriction profiles and this was used to calculate a similarity matrix based on the Dice similarity coefficient using SPSS 12.0. This matrix was used in a hierarchical cluster analysis utilizing the UPGMA (unweighed pair group method analysis) to construct a dendrogram using NTsys-PC 2.01b (Rohlf, 1997). The confidence level of this dendrogram was estimated by bootstrap analysis with Winboot (Yap and Nelson, 1996) with 5000 bootstrap replications. These analyses included all the observed submolar bands in the isolates since they usually belong to the most dominant genotype present in the virus population (Muñoz et al., 1998; Muñoz and Caballero, 2000; Simón et al., 2004).

\subsection{Bioassays}

A total of eight novel Iberian strains were identified by REN: HearNPV-SP3 (HearSP3), HearNPV-SP4 (HearSP4), HearNPV-SP5 (HearSP5), HearNPV-SP6 (HearSP6), HearNPV-SP7 (HearSP7), HearNPV-SP8 (HearSP8), HearNPV-PT1 (HearPT1) and HearNPV-PT2 (HearPT2). Viral pathogenicity expressed as 50\% lethal concentration $\left(\mathrm{LC}_{50}\right)$ and MTD were determined for HearSP4, HearSP7, HearSP8, HearPT1 and HearPT2. These strains were selected for testing because they showed the most distinct REN profiles. The HearSP2 strain was included as a reference.

To determine concentration-mortality responses, five different viral concentrations which were found to cause 5-95\% mortality in second instars in preliminary assays were used: $1 \times 10^{2}, 1 \times 10^{3}$, $1 \times 10^{4}, 1 \times 10^{5}$ and $1 \times 10^{6} \mathrm{OBs} / \mathrm{ml}$. OB concentrations were determined with an improved Neubauer hemocytometer under a phase contrast microscope at $400 \times$. Newly molted second instars from the laboratory colonies were individually separated to prevent cannibalism and starved for about $12 \mathrm{~h}$ at $20^{\circ} \mathrm{C}$. They were then allowed to drink viral suspensions containing $10 \%$ sucrose and $0.05 \%(\mathrm{w} / \mathrm{v})$ of the food dye, Fluorella Blue, by using the droplet-feeding method (Hughes and Wood, 1986). Groups of 25-30 larvae were used per concentration and viral isolate, and inoculated insects were individually transferred to 25 -well plates containing maize diet plugs. As controls, larvae were allowed drinking a water solution containing only the blue dye and sucrose at the same concentrations. Larvae were incubated at $25 \pm 1{ }^{\circ} \mathrm{C}, 70 \pm 5 \%$ relative humidity and $16: 8 \mathrm{~h}$ day-night photoperiod. Mortality was recorded every $24 \mathrm{~h}$ for 10 days. The experiment was replicated four times and about 100 larvae were used in total per concentration and viral isolate.

To determine time-mortality responses, similar bioassays were performed. For these, only the concentration causing the highest mortality was used $\left(1 \times 10^{6} \mathrm{OBs} / \mathrm{ml}\right)$. Mortality was recorded at $8 \mathrm{~h}$ intervals for 10 days. Larvae that did not die during the assay were not included in the analysis. Similarly, replicates in which 90\% mortality was not achieved after applying Abbott's correction for control mortality, were also discarded.

\subsection{Statistical analysis}

Concentration-mortality data were subjected to Probit analysis (Finney, 1971) using the POLO-PC program (LeOra Software, 1987). The relative potencies were estimated and compared as described by Robertson and Preisler (1992). Time-mortality results of individuals that died due to NPV infection by different isolates were subjected to Weibull analysis (Aitikin et al., 1989). The validity of the Weibull model was determined using the Kaplan macro present in the GLIM program.

\section{Results}

\subsection{Identification of NPV strains present in Iberian isolates}

The number of field-collected larvae from the Iberian Peninsula with baculovirus infection symptoms and the number of larvae in which the presence of OBs was detected by microscopic inspection is presented in Table 1.

From the seven field-collected isolates from Olivenza, Spain (Table 1), five different REN profiles were obtained with both BglII and PstI. Similarly, the three isolates from Toledo, Spain and the ten isolates from Oeste, Portugal, each exhibited two distinct REN profiles. In total, eight distinctive strains were obtained by combining the isolates BglII and PstI profiles from all locations (Fig. 1). Seven of these strains (HearSP3, HearSP4, HearSP5, HearSP7, HearSP8, HearPT1, and HearPT2) could be differentiated based on their BglII profiles alone (Fig. 1b). An additional isolate, HearSP6, which showed a BglII profile identical to HearSP5 could be distinguished from all the others with PstI (Fig. 1c). All the different isolates sharing the same HearNPV strain came from the same origin (two isolates from Olivenza consisting of HearSP7; two from Toledo of HearSP8, two from Oeste of HearPT1 and eight from Oeste of HearPT2) except HearSP5, which was found in two isolates from Olivenza and one isolate from Toledo.

All Iberian strains exhibited the BglII fragments A, I, J, K, and M as well as the PstI fragments A, B, C, E and F, whereas the presence of the BglII fragments B, C, D, E, F G, H and L and the Pstl fragment D varied among the strains (Fig. 1b, c, and d). The BglII fragments b1, $\mathrm{f} 1, \mathrm{~g} 1, \mathrm{~h} 1, \mathrm{i1}, \mathrm{i} 2, \mathrm{j} 1$, and PstI fragment d1 have strain recognition value (Fig. 1b, c, and d). Strains HearSP1, HearSP2, HearSP3, HearSP4, and HearPT1 presented submolar BglII fragments while HearSP6, displayed a submolar Pstl fragment, indicating that they were composed of a mixture of different genotypes (Fig. 1b, c and d). BglII fragment $\mathrm{f} 1$, which is only present in HearSP4, seems to be similar to one present in a Russian isolate profile analyzed by Figueiredo et al. (1999).

The Chinese HearG4 genotype displays a BglII profile in which only four out of 13 fragments show the same molecular weight to those of HearSP1 (Fig. 1a) but its PstI profile is identical to that of the Iberian strains (not shown).

\subsection{Cluster analysis of the Iberian HearNPV strains}

The strains presented some polymorphism (Dice coefficient $\geqslant 0.69$ ). The cophenetic correlation (correlation between the cophenetic value matrix and the similarity matrix upon which the clustering was based) was equal to 0.90 (Mantel $t$-test $=6.37$ ), revealing a good fit for the cluster analysis. Some of the strains were more closely related to geographically distant strains than to those collected in the same location, as observed by the cluster dendrogram (Fig. 2). In fact, taking into account a similarity threshold of $87 \%$, four groups can be identified: (1) HearSP1, HearSP2, HearPT1 and HearPT2, (2) HearSP3, HearSP5, HearSP6 and HearSP7, (3) HearSP8, and (4) HearSP4. The HearSP4 and HearSP8 strains were the most different and, even at lower estimated similarities (77\%), they continued to be separated from all the others.

The bootstrap estimate of the dendrogram (consensus tree) was equal to that obtained by NTsys, excluding the HearPT1 strain, which was placed separated from the cluster formed by HearSP1, HearSP2, and HearPT2 at a Dice similarity coefficient value of 0.87 and within the cluster formed by HearSP3, HearSP5, HearSP6, 

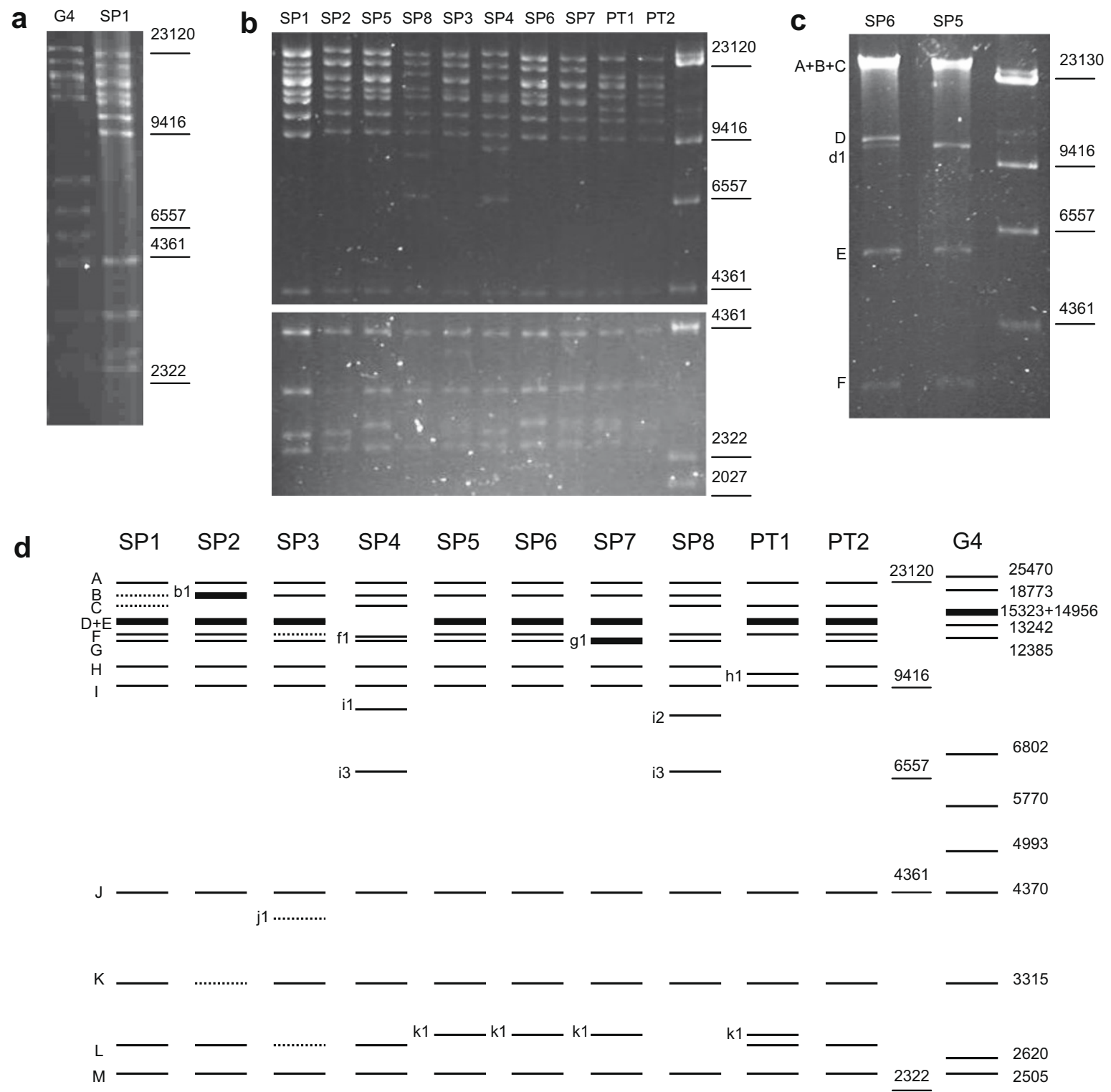

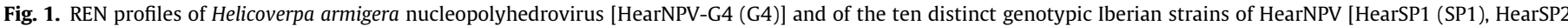

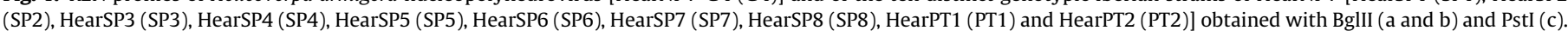

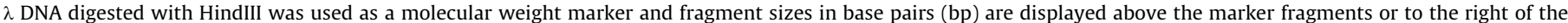

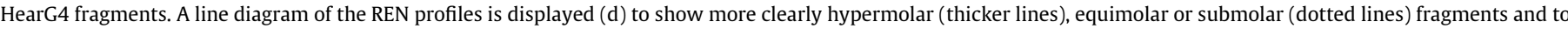

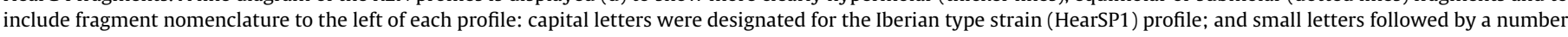
for the polymorphic fragments appearing in different strains.

and HearSP7 at the same Dice value (Fig. 2). This is also the position at which the UPGMA cluster analysis places HearPT1 when submolar bands are not considered (dendrogram not shown).

\subsection{Biological activity of six Iberian HearNPV strains}

Regressions lines for all six virus strains fitted the Probit model well $\left(\chi^{2}=29.21, d f=10 ; p=0.001\right)$ but they could not be fitted in parallel $\left(\chi^{2}=15.64 ; d f=5 ; p=0.008\right)$. The $\mathrm{LC}_{50}$ ratios indicated that HearSP7 and HearPT2 were 2.6- and 2.8-fold more pathogenic, respectively, than HearSP2 which showed the highest $\mathrm{LC}_{50}$ values. The $\mathrm{LC}_{50}$ values of HearSP4, HearSP8, and HearPT1 were statistically similar to that of HearSP2 (Table 2).

The different strains killed between 95.5 and $97.7 \%$ of the treated second instars and in a time range of 64-160 hpi (hours post-infection), with the exception of four larvae that died later
(176-232 hpi). The MTD values for the different strains ranged from $98.4 \mathrm{hpi}$ (HearPT2) to $115.2 \mathrm{hpi}$ (HearSP8). HearSP4 and HearPT2 both killed larvae significantly faster than HearSP8, whereas HearSP2, HearSP7 and HearPT1 showed intermediate MTD values that were not significantly different from those of HearSP4, HearPT2 or HearSP8 (Fig. 3). The instantaneous risk of death increased over time (shape parameter of the Weibull distribution $\alpha=3.87$ ). Time-mortality distribution curves peaked twice: once at $72-$ 80 hpi and again at $112-120$ hpi (data not shown).

\section{Discussion}

The REN profiles of all the strains analyzed in this work were very similar but not identical to those of the HearNPV isolates described by Figueiredo et al. (1999), indicating that they constitute novel HearNPV strains. The novel strains represented $40 \%$ of the to- 


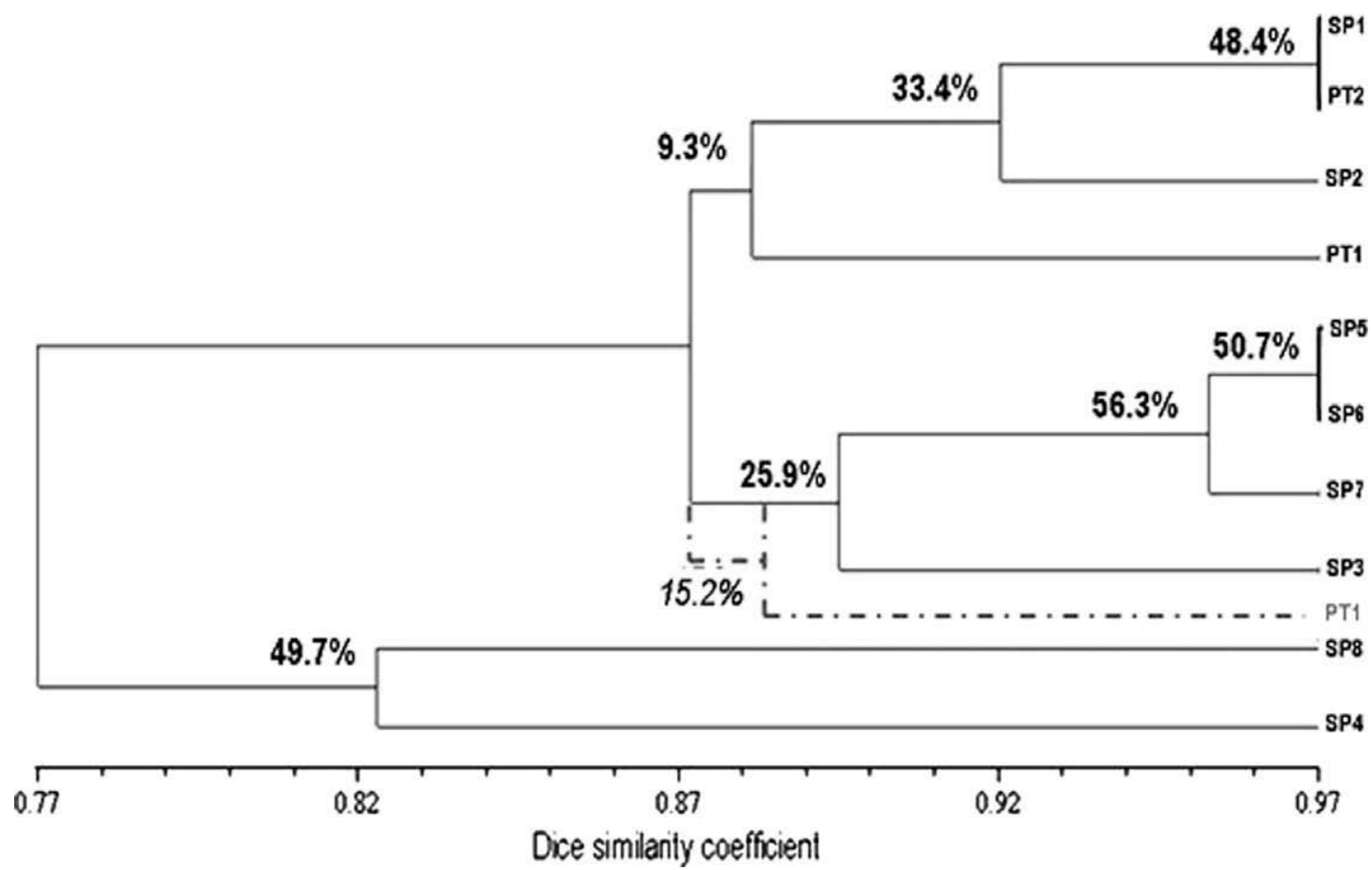

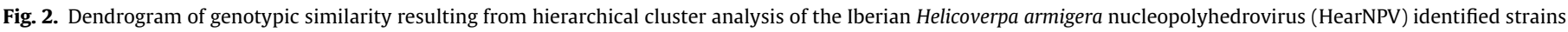

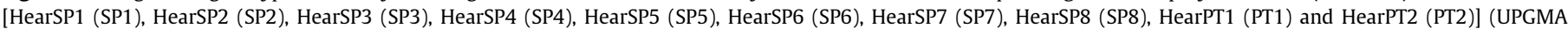

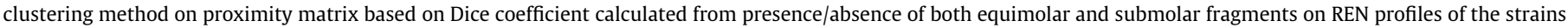

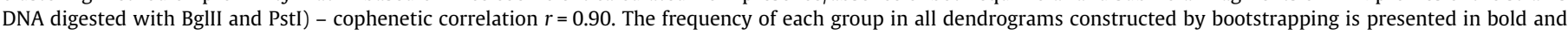

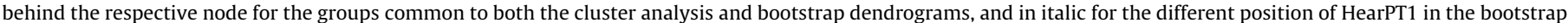
dendrogram (marked with a dotted line).

Table 2

Concentration-mortality responses for six Helicoverpa armigera nucleopolyhedrovirus (HearNPV) strains on second instar H. armigera larvae.

\begin{tabular}{|c|c|c|c|c|c|c|c|c|}
\hline \multirow[t]{2}{*}{ Strain $^{a}$} & \multirow[t]{2}{*}{ Intercept \pm SE } & \multirow[t]{2}{*}{ Slope $\pm \mathrm{SE}^{\mathrm{b}}$} & \multirow[t]{2}{*}{$\chi^{2}$} & \multirow[t]{2}{*}{$p$} & \multirow[t]{2}{*}{$\mathrm{LC}_{50}(\mathrm{OBs} / \mathrm{ml})^{\mathrm{c}}$} & \multirow[t]{2}{*}{ Potency $^{\mathrm{d}}$} & \multicolumn{2}{|c|}{ 95\% Fiducial limits } \\
\hline & & & & & & & Lower & Upper \\
\hline HearSP2 & $-4.87 \pm 0.65$ & $1.07 \pm 0.13 \mathrm{~b}$ & 2.32 & 0.51 & 34897 & $1.00 \mathrm{a}$ & - & - \\
\hline HearSP4 & $-3.85 \pm 0.49$ & $0.87 \pm 0.10 a b$ & 2.74 & 0.43 & 26149 & $1.34 \mathrm{a}$ & 0.78 & 2.30 \\
\hline HearSP7 & $-3.40 \pm 0.43$ & $0.82 \pm 0.09 a b$ & 2.06 & 0.56 & 13399 & $2.59 \mathrm{~b}$ & 1.55 & 4.33 \\
\hline HearSP8 & $-3.08 \pm 0.39$ & $0.71 \pm 0.08 \mathrm{a}$ & 2.25 & 0.52 & 20043 & $1.74 \mathrm{ab}$ & 0.69 & 4.41 \\
\hline HearPT1 & $-4.66 \pm 0.57$ & $1.09 \pm 0.12 b$ & 1.56 & 0.67 & 18687 & $1.86 \mathrm{ab}$ & 0.96 & 3.61 \\
\hline HearPT2 & $-3.13 \pm 0.39$ & $0.77 \pm 0.08 \mathrm{ab}$ & 2.35 & 0.53 & 12327 & $2.83 \mathrm{~b}$ & 1.44 & 5.57 \\
\hline
\end{tabular}

Probit regression (pooled data from four replications).

a HearNPV isolates from Spain and Portugal. See text and Table 1 for origin of isolates.

b SE, Standard error; slopes followed by the same letter were not different at $p=0.05$.

c OBs, Occlusion bodies.

d Potency (i.e., lethal concentration ratios with respect to that of HearSP2) followed by the same letter were not different at $p=0.05$.

tal number of isolates collected (larval cadavers where OBs were observed), but this figure may not be a realistic representation of field diversity, as no systematic effort at sampling was performed. Two different strains were identified in each of the three geographical regions surveyed, indicating a high variability of variants within each collection site. This is probably because the analysis was performed from individual cadavers, which increases the chances of quantifying the diversity present compared to analyses based on isolates composed of pooled groups of larval cadavers. Also, all isolates sharing the same HearNPV strain came from the same origin, except HearSP5, which was found in two isolates from Olivenza and one isolate from Toledo. It is fairly common to find the same strain in isolates from different origins, especially from sites geographically so close (Laitinen et al., 1996; Cooper et al., 2003; Graham et al., 2004).

Interestingly, intraspecific diversity was detected among the eight HearNPV strains identified. Within strains HearSP3, HearSP4 and HearPT1, a mixture of different genotypic variants was detected, as indicated by the presence of submolar bands in their corresponding REN profiles. These results suggest that insects were not infected by single variants but rather a mixture of them in a single isolate. This is a common phenomenon in baculovirus wild-type isolates, which are usually formed by a mixture of genotypes in distinct proportions (Muñoz et al., 1998; Murillo et al., 2001; Kamiya et al., 2004) even when obtained from single host individuals (Cherry and Summers, 1985; Graham et al., 2004; Cory et al., 2005), as occurred in our study. Furthermore, the absence of submolar bands is not a guarantee of the presence of a single genotype within the isolate (Vickers et al., 1991).

Some strain groups were highly similar with a relatively high bootstrap value. These strains were also placed together using other methods of classification (nearest neighbor, average linkage between groups or within groups - data not shown). It should be noted that the cluster analysis presented here was based on 


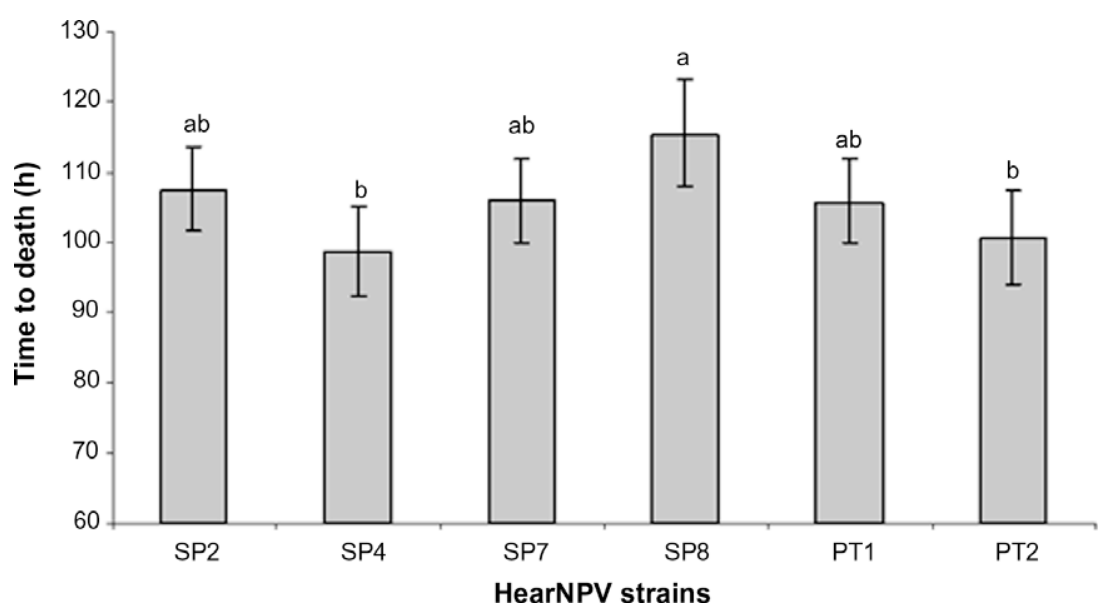

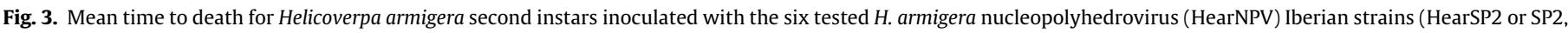
HearSP4 or SP4, HearSP7 or SP7, HearSP8 or SP8, HearPT1 or PT1 and HearPT2 or PT2) at a 95\% lethal concentration. Vertical bars indicate SE.

presence/absence of fragments with similar electrophoretic mobility and not in the similarity/divergence of the genome. Therefore, the strain clustering data can only be considered as an approximation of phylogenetic relatedness.

Genotype phylogeny was not found to be associated with geographical origin; the most related genotypes were not always the ones from the same or closely located sites. REN analysis of several Heliothinae NPVs verified that some strains were more closely related to a geographically distant strain than to those originating from a closer location (Gettig and McCarthy, 1982; Figueiredo et al., 1999), which is not unexpected due to the high migration abilities of Heliothinae species (Fitt, 1989). Migrations allow the transport of associated NPVs over long distances and their importance on the distribution patterns of NPVs was previously emphasized by Shapiro et al. (1991), Takatsuka et al. (2003) and Fuxa (1987). Moreover, HearNPV populations may be dispersed by insectivorous birds (Entwistle et al., 1993) and larval parasitoids (Young and Yearian, 1989). Such organisms are very frequent in the Portuguese and Spanish fields and greenhouses as natural enemies of noctuids (Meierrose et al., 1989; Figueiredo and Mexia, $2000)$. On the other hand, the well known variability of NPV genomes contributes to differentiate closely located genotypes. The high number of variants per site and the near absence of common strains among sites reveal the high genomic plasticity of HearNPV and suggest that, along with NPV strain dispersion, genotypic selection also occurs within individual larvae, as suggested by Graham et al. (2004). Without a doubt, intrapopulation diversity within a single host is ecologically relevant as the larva represents the basic unit of virus inoculum (Cooper et al., 2003). In addition, the maintenance of diversity may be an important mechanism for virus adaptation and survival under different conditions (e.g., host density, host resistance, host plant), and therefore, represent an evolutionary advantage for the virus (Cory and Myers, 2004).

Concentration-mortality assays resulted in significant differences among the Iberian HearNPV strains; $\mathrm{LC}_{50}$ values differed by 2.5-fold among strains. This level of heterogeneity in HearNPV was also reported by Zhang et al. (2005) between two Chinese isolates. The estimated $\mathrm{LC}_{50}$ values were similar to those reported by other authors for isolates from Africa (Ogembo et al., 2005) and China (Sun et al., 2004).

Differences among strains in the mean speed to kill varied only moderately since the difference between the slowest and fastest virus was only of about $16 \mathrm{~h}$. The MTD values obtained for the Iberian isolates were similar to those reported for the fastest-killing Heliothinae SNPV isolates studied by Hughes et al. (1983), which included
HearNPV strains from South Africa and Australia, a Helicoverpa zea SNPV from the US $\left(\right.$ Elcar $\left.^{\circledR}\right)$, a Helicoverpa punctigera SNPV from Australia, and a Heliothis virescens SNPV from the US. In fact, Hughes et al. (1983) verified that the most virulent isolates had lethal time ( $\left.\mathrm{LT}_{50}\right)$ values ranging from 72.8 to $79.6 \mathrm{~h}$ in neonates. In contrast, the MTD values obtained in our study seemed to be lower than those obtained by Ogembo et al. (2005), who reported MTD values of 6.5 days for second instars inoculated with similar concentrations. MTD values were also lower than those obtained by Teakle et al. (1985), who reported a $\mathrm{LT}_{50}$ value of 4.1-4.5 days for second instars. In contrast, our results were more similar to those of Williams and Payne (1984) with neonates and third-instar larvae.

The strategy to control $H$. armigera will probably be based on inundative applications of a microbial insecticide using a highly virulent strain/variant. Therefore, strains HearPT2, HearPT1, and HearSP7 seem to be the best candidates for potential insecticidal formulations, although extensive field evaluation is required.

Finally, these results can contribute to understand how HearNPV varies spatially in natural insect populations. This information is important in understanding baculovirus-insect evolution, design pest control programs, and in assessing the environmental impact of viral releases (Cory et al., 2005). Further analysis of the genotypic composition of these strains and their individual biological activities as well as comparison with strains from other regions of Iberia, North Africa and France, the immediate migration areas for the Iberian $H$. armigera populations, would give a broader picture of the ecology and evolution of this virus.

\section{Acknowledgments}

We thank L.M. Torres-Vila for collecting some diseased insects, the staff at EAN and UPNA for insect rearing, EAN-Genetics Department for use of their facilities and Arlindo Lima for assistance with NTsys analysis. The study was financed by a Spanish Ministerio de Asuntos Exteriores grant to E.F. and a Portuguese national project PO AGRO 189.

\section{References}

Aitikin, M.D., Anderson, D., Francis, B., Hindle, J., 1989. Statistical Modelling in GLIM Oxford, Science Publishers, Oxford, UK.

Caballero, P., Zuidema, D., Santiago-Alvarez, C., Vlak, J.M., 1992. Biochemical and biological characterization of four isolates of Spodoptera exigua nuclear polyhedrosis virus. Biocontrol Science and Technology 2, 145-157.

Chen, X., IJkel, W.F.J., Tarchini, R., Sun, X., Sandbrink, H., Wang, H., Peters, S., Zuidema, D., Lankhorst, R.K., Vlak, J., Hu, Z., 2001. The sequence of the 
Helicoverpa armigera single nucleocapsid nucleopolyhedrovirus genome. Journal of General Virology 82, 241-257.

Cherry, C.L., Summers, M.D., 1985. Genotypic variation among wild isolates of two nuclear polyhedrosis viruses from Spodoptera littoralis. Journal of Invertebrate Pathology 46, 289-295.

Cooper, D., Cory, J.S., Myers, J., 2003. Hierarchical spatial structure of genetically variable nucleopolyhedroviruses infecting cyclic populations of western tent caterpillars. Molecular Ecology 12, 881-890.

Cory, J.S., Green, B.M., Paul, R.K., Hunter-Fujita, F., 2005. Genotypic and phenotypic diversity of a baculovirus population within an individual insect host. Journal of Invertebrate Pathology 89, 101-111.

Cory, J.S., Myers, J.H., 2004. Adaptation in an insect host-plant pathogen interaction. Ecological Letters 7, 632-639.

Entwistle, P.F., Forkner, A.C., Green, B.M., Cory, J.S., 1993. Avian dispersal of nuclear polyhedrosis viruses after induced epizootics in the pine beauty moth, Panolis flammea (Lepidoptera: Noctuidae). Biological Control 3, 61-69.

Figueiredo, E., Amaro, F., Gonçalves, C., Godinho, M.C., Salvado, E., Albano, S., 2006. Lagarta do tomate. In: Amaro, F., Mexia, A. (Eds.), Protecção Integrada em Tomate de Indústria. Estação Agronómica Nacional (EAN). INIAP, Oeiras, Portugal, pp. 42-50.

Figueiredo, E., Mexia, A., 2000. Parasitoid complex associated with Lepidoptera on horticultural protected crops in the Oeste region of Portugal. IOBC/wprs Bulletin 23 (1), 205-208

Figueiredo, E., Muñoz, D., Escribano, A., Mexia, A., Vlak, J.M., Caballero, P., 1999. Biochemical identification and comparative insecticidal activity of nucleopolyhedrovirus pathogenic for Heliothis armigera (Lep., Noctuidae) larvae. Journal of Applied Entomology 123, 165-169.

Finney, D.J., 1971. Probit Analysis. Cambridge University Press, Cambridge, UK.

Fitt, G.P., 1989. The ecology of Heliothis species in relation to agroecosystems. Annual Review of Entomology 34, 17-52.

Fuxa, J.R., 1987. Spodoptera frugiperda susceptibility to nuclear polyhedrosis virus isolates with reference to insect migration. Environmental Entomology 16, 218-223.

Gettig, R.R., McCarthy, W.J., 1982. Genotypic variation among isolates of Heliothis spp. nuclear polyhedrosis viruses from different geographical regions. Virology $117,245-251$.

Graham, R.I., Tyne, W.I., Possee, R.D., Sait, S.M., Hails, R., 2004. Genetically variable nucleopolyhedroviruses isolated from spatially separate populations of the winter moth Operophtera brumata (Lepidoptera: Geometridae) in Orkney. Journal of Invertebrate Pathology 87, 29-38.

Harper, J.D., 1986. Interactions between baculoviruses and other entomopathogens, chemical pesticides, and parasitoids. In: Granados, R.R., Federici, B.A. (Eds.), The Biology of Baculoviruses, Practical Application for Insect Control, vol. I. CRC Press, Boca Raton, FL, pp. 133-156.

Hughes, P.R., Gettig, R.R., McCarthy, W.J., 1983. Comparison of the time-mortality response of Heliothis zea to 14 isolates of Heliothis nuclear polyhedrosis virus. Journal of Invertebrate Pathology 41, 256-261.

Hughes, P.R., Wood, H.A., 1986. In vivo and in vitro bioassay methods for baculoviruses. In: Granados, R.R., Federici, B.A. (Eds.), The Biology of Baculoviruses, Practical Application for Insect Control, vol. II. CRC Press, Boca Raton, FL, pp. 1-30.

Jones, K.A., Zelazny, B., Ketunuti, U., Cherry, A., Grzywacz, D., 1998. World survey. South-east Asia and the western Pacific. In: Hunter-Fujita, F.R., Entwistle, P.F. Evans, H.F., Crook, N.E. (Eds.), Insect Viruses and Pest Management. John Wiley \& Sons, Chichester, UK, pp. 244-257.

Kamiya, K., Zhu, J., Murata, M., Laviña-Caoili, B.A., Ikeda, M., Kobayashi, M. Kawamura, S., 2004. Cloning and comparative characterization of three distinct nucleopolyhedroviruses from the common cutworm Spodoptera litura (Lepidoptera: Noctuidae) in Japan. Biological Control 31, 38-48.

Laitinen, A.M., Otvos, I.S., Levin, D.B., 1996. Genotypic variation among wild isolates of Douglas-fir tussock moth (Lepidoptera: Lymantriidae) nuclear polyhedrosis virus. Journal of Economic Entomology 89, 640-647.

Software, LeOra, 1987. POLO-PC A User's Guide to Probit or Logit Analysis. Berkeley, CA

McCaffery, A., 1998. Resistance to insecticides in heliothine Lepidoptera: a global view. Philosophical Transactions of the Royal Society of London B 353, 17351750.

Meierrose, C., Araújo, J., Perkins, D., Mercadier, G., Poitout, S., Bues, R., VargasPiqueras, P., Cabello, T., 1989. Distribution and economic importance of Heliothis spp. (Lep.: Noctuidae) and their natural enemies and host plants in Western Europe. In: King, E.G., Jackson, R.D. (Eds.), Proc. Workshop Biological Control of
Heliothis: Increasing the Effectiveness of Natural Enemies, 11-15 Nov. 1985, New Delhi. US Dep. Agric., New Delhi, India, pp. 311-327.

Milks, L.C., 1997. Comparative biology and susceptibility of cabbage looper (Lepidoptera: Noctuidae) lines to a nuclear polyhedrosis virus. Environmental Entomology 26, 839-848.

Moscardi, F., 1999. Assessment of the application of baculoviruses for control of Lepidoptera. Annual Review of Entomology 44, 257-289.

Muñoz, D., Caballero, P., 2000. Persistence and effects of parasitic genotypes in a mixed population of the Spodoptera exigua nucleopolyhedrovirus. Biological Control 19, 259-264.

Muñoz, D., Castillejo, J.I., Caballero, P., 1998. Naturally occurring delection mutants are parasitic genotypes in a wild-type nucleopolyhedrovirus population of Spodoptera exigua. Applied and Environmental Microbiology 64, 4372-4377.

Murillo, R., Muñoz, D., Lipa, J.J., Caballero, P., 2001. Biochemical characterization of three nucleopolyhedrovirus isolates of Spodoptera exigua and Mamestra brassicae. Journal of Applied Entomology 125, 267-270.

Ogembo, J.G., Kunjeku, E.C., Sithanantham, S., 2005. A preliminary study on the pathogenicity of two isolates of nucleopolyhedroviruses infecting the African bollworm, Helicoverpa armigera (Lepidoptera: Noctuidae). International Journal of Tropical Insect Science 25, 218-222.

Poitout, S., Bues, R., 1974. Élevage des chenilles de vingt-huit espèces de lépidoptéres Noctuidae et de deux espèces d'Arctiidae sur milieu artificiel simple. Particularités de l'élevage selon les espèces. Annales de Zoologie. Ecologie Animale 6, 431-441.

Raymond, B., Sayyed, A.H., Wright, D.J., 2006. The compatibility of a nucleopolyhedrovirus control with resistance for Bacillus thuringiensis: coinfection and cross resistance studies with the diamondback moth, Plutella xylostella. Journal of Invertebrate Pathology 93, 114-120.

Robertson, J.L., Preisler, H.K., 1992. Pesticide Bioassays with Arthropods. CRC, Boca Raton, FL.

Rohlf, F.J., 1997. NTSYS-PC. Numerical Taxonomy and Multivariate Analysis System. Version 2.00. Exeter Software, Setauket, New York

Shapiro, D.I., Fuxa, J.R., Braymer, H.D., Pashley, D.P., 1991. DNA in wild isolates of Spodoptera frugiperda nuclear polyhedrosis virus. Journal of Invertebrate Pathology 58, 96-105.

Simón, O., Williams, T., López-Ferber, M., Caballero, P., 2004. Genetic structure of a Spodoptera frugiperda nucleopolyhedrovirus population: high prevalence of deletion genotypes. Applied and Environmental Microbiology 70, 5579-5588.

Sun, X., Wang, H., Sun, X., Chen, X., Peng, C., Pan, D., Jehle, J.A., Van der Wert, W., Vlak, J.M., Hu, Z., 2004. Biological activity and field efficacy of a genetically modified Helicoverpa armigera SNPV expressing an insect-selective toxin from a chimeric promoter. Biological Control 29, 124-137.

Takatsuka, J., Okuno, S., Nakai, M., Kunimi, Y., 2003. Genetic and biological comparisons of ten geographic isolates of a nucleopolyhedrovirus that infects Spodoptera litura (Lepidoptera: Noctuidae). Biological Control 26, 32-39.

Teakle, R.E., Jensen, J.M., Giles, J.C., 1985. Susceptibility of Heliothis armigera to a commercial nuclear polyhedrosis virus. Journal of Invertebrate Pathology 46, 166-173.

Torres-Vila, L.M., Rodríguez-Molina, M.C., Lacasa-Plasencia, A., Bielza-Lino, P., Rodríguez-del-Rincón, A., 2002. Pyrethroid resistance of Helicoverpa armigera in Spain: current status and agroecological perspective. Agriculture Ecosystems and Environment 93, 55-66.

Vickers, J.M., Cory, J.S., Entwistle, P.F., 1991. DNA characterisation of eight geographic isolates of granulosis virus from the potato tuber moth (Phthorimaea operculella) (Lepidoptera, Gelechiidae). Journal of Invertebrate Pathology 57, 334-342.

Wang, H., Chen, X., Wang, H., Arif, B., Vlak, J., Hu, Z., 2001. Nucleotide sequence and transcriptional analysis of a putative basic DNA-binding protein of Helicoverpa armigera nucleopolyhedrovirus. Virus Genes 22, 113-120.

Williams, C., Payne, C.C., 1984. The susceptibility of Heliothis armigera larvae to three nuclear polyhedrosis viruses. Annals of Applied Biology 104, 405-412.

Yap, I.V., Nelson, R.J., 1996. WinBoot: A Program for Performing Bootstrap Analysis of Binary Data to Determine the Confidence Limits of UPGMA-Based Dendrograms. IRRI, Manila, Philippines.

Young, S.Y., Yearian, W.C., 1989. Nuclear polyhedrosis virus transmission by Microplitis croceipes (Hymenoptera: Braconidae) adult females reared in infected Heliothis virescens (Lepidoptera: Noctuidae) larvae. Journal of Entomological Science 24, 500-506.

Zhang, C.X., Ma, X.C., Guo, Z.J., 2005. Comparison of complete genome sequence between C1 and G4 isolates of the Helicoverpa armigera single nucleocapsid nucleopolyhedrovirus. Virology 333, 190-199. 